\section{Effects of Iloprost on Microvascular Structure Assessed by Nailfold Videocapillaroscopy: A Pilot Study}

\section{To the Editor:}

In patients with systemic sclerosis (SSc), both structural and functional abnormalities of the microvasculature occur ${ }^{1}$, often resulting in severe digital ischemia with ulceration, scarring, and sometimes even gangrene. The structural abnormalities are well demonstrated by nailfold capillaroscopy ${ }^{2}$, especially using high magnification videocapillaroscopy ${ }^{3}$, which allows measurement of capillary density and dimensions.

Intravenous (IV) prostanoids, such as iloprost and epoprostenol, are currently the mainstay of treatment for severe SSc-related digital ischemia $^{4,5}$. In the UK, iloprost is most commonly used. As well as being a potent vasodilator, iloprost inhibits platelet aggregation and is thought also to have vascular remodeling properties ${ }^{6}$. A key issue is whether IV prostanoids might prevent or even reverse SSc-related microvascular changes; if so, this would be an indication to use these drugs more widely, especially in patients with early disease, in whom microvascular changes are more likely to be reversible than in those with well established problems. We performed a pilot study to investigate whether administration of IV iloprost was associated with structural changes in the digital microvasculature as quantified by nailfold videocapillaroscopy.

Nine patients with SSc (7 female) in whom IV iloprost was clinically indicated for the treatment of digital ischemia or digital ulceration were recruited, and a tenth patient with $\mathrm{SSc}$ in whom the indication for iloprost was progressive skin thickening with incipient forearm ulceration. Seven had limited cutaneous SSc and 3 diffuse cutaneous $\mathrm{SSc}^{7}$. Their median age was 51 years (range 33 to $68 \mathrm{yrs}$ ), median duration of Raynaud's phenomenon 13 years (range 0.5-36 yrs), and their median SSc disease duration (from onset of the first non-Raynaud's clinical feature) was 7 years (range $0.5-13 \mathrm{yrs}$ ). Five were anticentromere antibody-positive and one was anti-Scl-70 antibody-positive. Intravenous iloprost was given to each patient for 6 hours per day for 5 consecutive days, maximal dose $2 \mathrm{ng} / \mathrm{kg} / \mathrm{min}$.

Nailfold capillaries were imaged using videomicroscopy at high magnification $(\times 300)$ in the nondominant ring finger as described ${ }^{8}$. Computerized software allowed the same nailfolds to be tracked over subsequent visits ${ }^{8}$. The number of capillaries in the distal row per millimeter was recorded, as well as the total capillary width and apical width. Dimensions were the mean of the first 5 trackable capillaries, measured on Day 1 (pre-iloprost), Day 3, and Day 5 (immediately post-iloprost) and 12 months following iloprost. The observer measuring capillary density and dimensions was blinded to the subject and to the visit number. Clinical response to IV iloprost was assessed by patient perception of the degree of severity of Raynaud's phenomenon on a 100-mm visual analog score. Differences in capillary measurements from baseline were assessed using Wilcoxon's signed-rank test, and differences in visual analog scores using a paired $t$ test. The study was approved by the Salford and Trafford Local Ethics Committee and all patients provided signed informed consent.

Median (range) results on Day 1 (pre-iloprost), 3, and 5 (immediately post-iloprost) and at 12 months are shown in Table 1. While there was a trend for capillary density to increase immediately following iloprost $(\mathrm{p}=$ $0.07)$, this was not sustained at 12 months. There was a trend toward a decrease in apical width 12 months post-iloprost $(\mathrm{p}=0.09)$. There was a statistically significant improvement in symptoms related to Raynaud's phenomenon immediately following iloprost $(\mathrm{p}<0.05)$, an improvement maintained at 12 months.

This was a small pilot study and the clinical relevance of the observed capillaroscopic changes is unclear. The trends toward increased density immediately following iloprost, and reduced apical width 12 months post-iloprost are, however, encouraging and deserve further study, as they suggest that vascular remodeling effects may be a measurable phenomenon in the digital miscrovasculature. Nailfold capillaroscopy visualizes the column of red blood cells within the capillary rather than the capillary itself (which is invisible with a light microscope), and so it could be argued that it gives only an indirect measure of microvascular structure. However, we believe that the acclimatization period at $23^{\circ} \mathrm{C}$, and the image-capture system that digitizes a series of 16 videoframes rather than relying on a single (instantaneous) image ${ }^{8}$, minimize the chance of some capillaries not being seen, and nailfold capillarosocpy is the best currently available noninvasive method of examining the morphology of the digital microcirculation.

More dramatic changes in nailfold capillary structure during and after iloprost therapy for digital ischemia have been reported anecdotally ${ }^{9}$, although only a small section of the nailbed was illustrated. The quantitative method used in our study for tracking capillaries, although having the advantage of displaying the whole nailfold as a "mosaic" , may have been relatively insensitive to change, in that dimensions were measured in only 5 capillaries. Also, we specifically selected 5 capillaries that were easy to measure, thus deliberately omitting some of the most abnormal loops, which may have been those most likely to demonstrate change. In addition, our study was observational and it is possible that iloprost may stabilize rather than improve capillary structure. This hypothesis could only be tested within a controlled trial.

We quantified capillary changes in relation to iloprost in SSc, using the unique window into the microcirculation provided by nailfold videocapillaroscopy to track change over time. While recognizing the limitations of a small observational study (including that other factors such as disease progression may influence the 12-month findings), nontheless we believe our findings are potentially very relevant: being able to quantify treatment response in terms of an improvement in microvascular structure is a major step forward. Further studies, incorporating larger numbers of patients with different stages of SSc-spectrum disorders, more than one nailbed in each patient, and improved methods of quantifying capillary change, are the next step.

PREETI SHAH, MRCP, Consultant Rheumatologist, Department of Rheumatology, Trafford Healthcare NHS Trust, Urmston; ANDREA K. MURRAY, PhD, Research Fellow; TONIA L. MOORE, BSc, Chief Physiological Measurement Technician; ARIANE L. HERRICK, FRCP, Reader in Rheumatology, The University of Manchester, Manchester Academic Health Science Centre, Salford Royal Hospital, Salford,

Table 1. Capillary dimensions and Raynaud's visual analog scores before, during, and after intravenous iloprost treatment. Results are median (range).

\begin{tabular}{lcccc}
\hline & Pre-Iloprost & Day 3 Iloprost & $\begin{array}{c}\text { Immediately } \\
\text { Post-Iloprost } \\
\text { (Day 5) }\end{array}$ & $\begin{array}{c}\text { 12 Months } \\
\text { Post-Iloprost }\end{array}$ \\
\hline Capillary density/mm & $6.0(3.3-7.3)$ & $6.5(3.3-7.9)$ & $6.9(3.7-8.8)$ & $6.2(3.7-8.9)$ \\
Total capillary width, $\mu \mathrm{m}$ & $94(49-268)$ & $97(35-280)$ & $96(55-240)$ & $78(47-193)$ \\
Apical width, $\mu \mathrm{m}$ & $37(20-129)$ & $36(11-137)$ & $31(24-182)$ & $28(15-81)$ \\
$\begin{array}{l}\text { Raynaud's visual } \\
\text { analog score, } \mathrm{mm}\end{array}$ & $59(0-79)$ & $22(0-69)^{*}$ & $12(3-72)$ & $32(10-83)$ \\
\hline
\end{tabular}

* Results from 7 patients only. 
M6 8HD, UK. Address correspondence to Dr. Herrick;

E-mail: ariane.herrick@manchester.ac.uk

\section{REFERENCES}

1. Herrick AL. Vascular function in systemic sclerosis. Curr Opin Rheumatol 2000;12:527-33.

2. Maricq HR, LeRoy EC. Patterns of finger capillary abnormalities in connective tissue disease by 'wide-field' microscopy. Arthritis Rheum 1973;16:619-28.

3. Herrick AL, Cutolo M. Clinical implications from capillaroscopic analysis in patients with Raynaud's phenomenon and systemic sclerosis. Arthritis Rheum 2010;62:2595-604.

4. Wigley FM, Wise RA, Seibold JR, McCloskey DA, Kujala G, Medsger TA, et al. Intravenous iloprost infusion in patients with Raynaud phenomenon secondary to systemic sclerosis. A multicenter, placebo-controlled, double-blind study. Ann Intern Med 1994;120:199-206.

5. Pope J, Fenlon D, Thompson A, Shea B, Furst D, Wells G, et al. Iloprost and cisaprost for Raynaud's phenomenon in progressive systemic sclerosis. Cochrane Database Syst Rev 1998;2:CD000953.

6. Fishman AP. Pulmonary hypertension - beyond vasodilator therapy. N Engl J Med 1998;338:321-2.

7. LeRoy EC, Black C, Fleischmajer R, Jablonska S, Kreig T, Medsger TA, et al. Scleroderma (systemic sclerosis): classification, subsets and pathogenesis. J Rheumatol 1988;15:202-5.

8. Anderson ME, Allen PD, Moore T, Hillier V, Taylor CJ, Herrick AL. Computerised nailfold video capillaroscopy - a new tool for the assessment of Raynaud's phenomenon. J Rheumatol 2005;32:841-8.

9. Pyrpasopoulou A, Aslanidis S. Clinical images: Iloprost-induced vascular remodeling. Arthritis Rheum 2007;56:2243.

J Rheumatol 2011;38:9; doi:10.3899/jrheum.110067 